\title{
Free and conjugated androgen and progestin levels in the serum of stellate sturgeon (Acipenser stellatus Pallas) males treated with female coelomic fluid
}

\author{
By L. Bayunova ${ }^{1,2}$, T. Semenkova ${ }^{1}$, A. V. M. Canario ${ }^{3}$, A. Gerasimov ${ }^{1}$ and I. Barannikova ${ }^{4}$ \\ ${ }^{1}$ Central Laboratory of Fish Reproduction, St Petersburg, Russia; ${ }^{2}$ Sechenov Institute of Evolutional Physiology and Biochemistry \\ of the Russian Academy of Sciences, St Petersburg, Russia; ${ }^{3}$ CCMAR, Universidade do Algarve, Campus de Gambelas, Faro, \\ Portugal; ${ }^{4}$ St Petersburg State University, Universitetskaya embankment, St Petersburg, Russia
}

\begin{abstract}
Summary
Based on the supposition that female coelomic fluid contents have a certain chemical influence on sturgeons, blood serum concentrations of free and conjugated testosterone (T), 11ketotestosterone $(11 \mathrm{KT}), \quad 17,20 \beta, 21$-trihydroxy-4-pregnen3-one (20 $\beta \mathrm{S}), \quad 17,20 \beta$-dihydroxy-4-pregnen-3-one (DHP), 11-desoxycortisol $(\mathrm{S})$ and free progesterone $\left(\mathrm{P}_{4}\right)$ have been measured by radioimmunoassay (RIA) and enzyme-linked immuno-sorbent assay (ELISA) in stellate sturgeon (Acipenser stellatus Pallas) males treated with female coelomic fluid (CF); $\mathrm{CF}$ steroid levels have also been analyzed. After treatment a significant elevation of free $20 \beta$ S and glucuronidated DHP and $\mathrm{S}$ levels and the decrease of free $\mathrm{T}$ and $\mathrm{KT}$ levels have been observed. The obtained data support the idea that the components of CF may play some part in pheromonal effects for sturgeon reproduction.
\end{abstract}

\section{Introduction}

It is well recognized that sex steroids play an important role in hormonal control of the reproduction in the animal kingdom, including fish (Kime, 1993; Barannikova et al., 2002). Fish use reproductive steroids as endogenous signals between reproductive tract and brain and as exogenous signals (pheromones) for gamete maturation synchronization and for spawning interactions among conspecifics. Sex steroids and their metabolites, as well as prostaglandins, have been demonstrated to have pheromonal effects at least in some Teleostei (see review by Stacey and Sorensen, 2002; Sorensen et al., 2004; Burnard et al., 2008).

One of the best known pheromonal systems in teleosts is described for goldfish (Carassius auratus) which releases preand post-ovulatory pheromones (Kobayashi et al., 2002; Sorensen and Stacey, 2004). The main pre-ovulatory pheromones are androstendione, maturation inducing steroid 17,20 $\beta$-dihydroxy-4-pregnen-3-one (DHP) and its sulphated metabolite, the main postovulatory pheromones are prostaglandin F2 $\alpha$ and a metabolite 15-keto-prostaglandin F2 $\alpha$. Coelomic fluid (CF) has a pheromonal function including behavioral reactions in the spawning fish (Stacey and Goetz, 1982; Kasumyan, 1993; Scott and Vermeirssen, 1994). The amount of CF (or ovarian fluid or peritoneal fluid) which is released together with the eggs is about $10-30 \%$ of the total egg volume in the Salmonidae (Lahnsteiner and Weismann, 1999), and about $15-20 \%$ - in the Acipenseridae (Ginsburg and Dettlaff, 1969). As the amount of ovarian fluid is high it may surround the eggs during spawning. In brown trout (Salmo trutta f. fario), ovarian fluid in comparison to water, prolongs the duration of sperm motility for $>5 \mathrm{~min}$ and the fertilizability of eggs for $>10 \mathrm{~min}$ independent from the quality of the egg batch from which the ovarian fluid derived; these stabilizing effects are related to the inorganic composition of ovarian fluid (Lahnsteiner, 2002).

The aim of this investigation was to analyze free and conjugated (sulphated and glucuronidated) testosterone (T), 11-ketotestosterone (11KT), 17,20 $\beta, 21$-trihydroxy-4-pregnen3-one (20 $\beta \mathrm{S}), \quad 17,20 \beta$-dihydroxy-4-pregnen-3-one (DHP), 11-desoxycortisol $(\mathrm{S})$ and free progesterone $\left(\mathrm{P}_{4}\right)$ levels in the $\mathrm{CF}$ and in the serum in stellate sturgeon (Acipenser stellatus Pallas) males treated with female $\mathrm{CF}$ in order to proof that the $\mathrm{CF}$ components may have a role in pheromonal communications in sturgeons.

\section{Material and methods \\ Animals}

Stellate sturgeon (Acipenser stellatus Pallas) wild breeders were captured from the Volga River delta during May-June 2005 and transported (over 18-20 h) to the Zitnenskiy Sturgeon Hatchery (Volga River delta) using a special transport loading boat.

After delivery to the Sturgeon Hatchery stellate sturgeon males ( $\mathrm{n}=7,4.8 \pm 0.17 \mathrm{~kg}$ body weight) were placed in the indoor $12.5 \mathrm{~m}^{2}$-tank ( $1 \mathrm{~m}$ deep) using a flow of river water (about $0.05 \mathrm{~m}^{3} \mathrm{~min}^{-1}$ ) and held 6 days. Water temperature was $21.2-22^{\circ} \mathrm{C}$ during holding period in the tanks and during the experiment.

After delivery stellate sturgeon females were kept in the outdoor special holding pond $\left(1000 \mathrm{~m}^{2}, 1.2-1.7 \mathrm{~m}\right.$ deep; usually the loading density in the pond is one female per $10 \mathrm{~m}^{2}$ ) using a flow of river water (about $0.5 \mathrm{~m}^{3} \mathrm{~min}^{-1}$ ). Water temperature was $15.5-17.2^{\circ} \mathrm{C}$ during the holding period in the ponds. After 10 days of the pond holding period four females ( $\mathrm{n}=4,7.1 \pm 1.16 \mathrm{~kg}$ body weight) were maintained in the indoor $12.5 \mathrm{~m}^{2}$-tank $(1 \mathrm{~m}$ deep; flow of river water was about $\left.0.05 \mathrm{~m}^{3} \mathrm{~min}^{-1}\right)$ and treated by LH-RH-A (desGly ${ }^{10}$-[D-Ala $\left.{ }^{6}\right]-$ $\left.\mathrm{Pro}^{9}-\mathrm{NH}_{2}-\mathrm{Et}-\mathrm{LH}-\mathrm{RH}\right)$ to induce final maturation (FM). The temperature was $20.4-21.4^{\circ} \mathrm{C}$ during this period. Dissolved oxygen was $8.1-8.3 \mathrm{mg} \mathrm{l}^{-1}$ during at experiment and the $\mathrm{pH}$ ranged from 7.4 to 7.6 .

\section{Experimental design}

The water level in the tank with males was decreased from 1 to $0.14 \mathrm{~m}$ during experiment. CF $(0.7 \mathrm{~L})$ was collected from ovulated females $24 \mathrm{~h}$ before the experiment and stored 
refrigerated at $4-6^{\circ} \mathrm{C}$. The $\mathrm{CF}$ was diluted in the river water $(1: 10)$ before experiment and small portions $(500 \mathrm{ml})$ of this mixture were added $2 \mathrm{~min}$ interval for $0.5 \mathrm{~h}$ into water of tank containing males.

\section{Sampling procedure}

Four blood samples $(1.5 \mathrm{ml})$ were taken repeatedly from the caudal vein of males using a syringe: (i) $1-1.5 \mathrm{~h}$ before the treatment; (ii) $1 \mathrm{~h}$ after the treatment; (iii) $3 \mathrm{~h}$ after the treatment; (iv) $6 \mathrm{~h}$ after the treatment.

Blood and coelomic fluid samples were taken from the females after ovulation. Blood samples were held until separation of the serum. Then the samples were collected, frozen and stored at $-20^{\circ} \mathrm{C}$ until assayed for steroids.

\section{Steroid assays}

Concentrations $\left(\mathrm{ng} \mathrm{ml}^{-1}\right)$ of free, sulphated and glucuronidated testosterone $(\mathrm{T}), 11$-ketotestosterone $(11 \mathrm{KT}), 17,20 \beta, 21$-trihydroxy-4-pregnen-3-one (20 $\beta \mathrm{S}), 17,20 \beta$-dihydroxy-4-pregnen-3one (DHP) and 11-desoxycortisol (S) were measured by radioimmunoassay (RIA) (Canario and Scott, 1989; Scott and Canario, 1992). Concentrations $\left(\mathrm{ng} \mathrm{ml}^{-1}\right)$ of free progesterone $\left(\mathrm{P}_{4}\right)$ and $\mathrm{T}, 11 \mathrm{KT}$ in female serum were measured by enzyme linked immuno-sorbent assay (ELISA) (Semenkova et al., 2002). The standards and unknown serum and CF were analyzed in duplicates.

\section{Gamete quality evaluation procedure}

Egg quality was defined at gastrulation as a percentage of normal embryos (Ginsburg and Dettlaff, 1969).

\section{Statistical analysis}

The data were analysed using $t$-Student test and Pearson moment product correlations. All data are presented as the mean and standard error of the mean (SEM) and the level of significance established at $5 \%$.

\section{Results}

Composition of coelomic fluid in comparison to blood serum in the females

Three of four females matured and their fertilized eggs yielded $83.7 \pm 2.9 \%$ of normal embryos. Free and conjugated forms of sex steroids were detected in CF (Table 1). There were no significant differences between absolute concentrations of free and conjugated sex steroids in CF. There were positive correlations between free and conjugated $\mathrm{T}$ levels as well as between free and conjugated $\mathrm{S}$ levels, and between free and sulphated DHP levels.

The conjugated $\mathrm{T}$ levels were similar in blood serum and $\mathrm{CF}$ as well as free $\mathrm{P}_{4}$ levels. But free serum $\mathrm{T}$ levels were higher than free coelomic fluid $\mathrm{T}$ levels $(\mathrm{P}<0.01)$ as well as serum $11 \mathrm{KT}$ levels $(\mathrm{P}<0.05)$.

\section{Males}

Free 20 $\beta$ S levels significantly increased $1 \mathrm{~h}(\mathrm{P}<0.05)$ and $3 \mathrm{~h}$ $(\mathrm{P}<0.01)$ after the treatment and decreased at the end of experiment and its conjugated forms did not significantly change (Fig. 1).

Free DHP and S levels did not significantly change during experiment (Figs 2 and 3). Glucuronidated DHP $(\mathrm{P}<0.01)$ and $\mathrm{S}(\mathrm{P}<0.05)$ levels were elevated $1 \mathrm{~h}$ after the treatment.

Free $11 \mathrm{KT}$ levels decreased $1 \mathrm{~h}$ after the treatment $(\mathrm{P}<0.05)$ (Fig. 4). Free and conjugated $\mathrm{T}$ serum levels did not change significantly during experiment (Fig. 5). A slight rise of swimming activity in males as a behavioural reaction to the $\mathrm{CF}$ of females was observed.

\section{Discussion}

In some studies it was found that $\mathrm{CF}$ can improve the fertilization rates (Ginsburg and Dettlaff, 1969) and has a pheromonal function in the behaviour of the spawning fish including sturgeon (Kasumyan, 1993; Scott and Vermeirssen, 1994). We detected the free and conjugated forms of sex steroids in CF in stellate sturgeon. In some teleost, gonadal steroids have important roles as pheromones, but although a wide variety of chemicals have been proposed to function as pheromones, only for certain gonadal steroids and prostaglandins have the pattern of release, olfactory detection, and biological responsiveness have been characterized (Sorensen and Stacey, 2004).

The present study demonstrates that the free androgen levels were lower in the $\mathrm{CF}$ than in the blood serum. The results are in good agreement with our previous observations in sturgeon. According to our earlier data in Russian sturgeon (Acipenser gueldenstaedtii), androgen levels were lower in the CF than in the blood serum (Bayunova et al., 2003). In stellate sturgeon, $\mathrm{T}$ and cortisol levels were also significantly lower in the $\mathrm{CF}$

Table 1

The levels (ng ml${ }^{-1}$ ) of free and conjugated (sulphated and glucuronidated) testosterone (T), 11-ketotestosterone (11KT), 17,20 $\beta, 21$-trihydroxy-4pregnen-3-one $(20 \beta \mathrm{S}), 17,20 \beta$-dihydroxy-4-pregnen-3-one (DHP), 11-desoxycortisol $(\mathrm{S})$ and progesterone $\left(\mathrm{P}_{4}\right)$ in the stellate sturgeon female serum and coelomic fluid. Data present mean and standard error of the mean (SE). The serum and coelomic fluid unknown samples have been analyzed in duplicates; number of examined fish was $3(\mathrm{n}=3)$. Differences are significant for $\mathrm{T}$ and $11 \mathrm{KT}$ coelomic fluid levels in comparison to the serum levels: ${ }^{*} \mathrm{P}<0.05 ; * *<0.01$. Correlation coefficients $(r)$ were high positive between free and conjugated form for $\mathrm{T}$, DHP and $\mathrm{S}$

\begin{tabular}{|c|c|c|c|c|c|c|c|c|}
\hline \multirow[b]{2}{*}{ Steroid } & \multicolumn{2}{|l|}{ Free } & \multicolumn{3}{|l|}{ Sulphate } & \multicolumn{3}{|l|}{ Glucuronide } \\
\hline & Serum & Coelomic fluid & Serum & Coelomic fluid & $\begin{array}{l}\text { Correlation } \\
\text { coefficient, } r\end{array}$ & Serum & Coelomic fluid & $\begin{array}{l}\text { Correlation } \\
\text { coefficient, } r\end{array}$ \\
\hline $\mathrm{T}$ & $111.9 \pm 43.63$ & $8.9 \pm 3.50^{* *}$ & $2.5 \pm 0.94$ & $3.0 \pm 0.54$ & $0.789 ; \mathrm{P}<0.05$ & $1.7 \pm 0.28$ & $3.2 \pm 0.58$ & $0.908 ; \mathrm{P}<0.01$ \\
\hline $11 \mathrm{KT}$ & $9.5 \pm 2.34$ & $2.3 \pm 0.99 *$ & - & $1.37 \pm 0.35$ & & - & $1.4 \pm 0.22$ & \\
\hline $\mathrm{P}_{4}$ & $0.49 \pm 0.12$ & $0.53 \pm 0.1$ & - & - & & - & - & \\
\hline $20 \beta \mathrm{S}$ & - & $0.22 \pm 0.09$ & - & $0.33 \pm 0.15$ & & - & $0.18 \pm 0.01$ & \\
\hline DHP & - & $0.32 \pm 0.13$ & - & $0.45 \pm 0.11$ & $0.869 ; \mathrm{P}<0.01$ & - & $0.39 \pm 0.17$ & \\
\hline $\mathrm{S}$ & - & $0.17 \pm 0.03$ & - & $0.18 \pm 0.07$ & $0.677 ; \mathrm{P}<0.05$ & - & $0.17 \pm 0.04$ & $0.859 ; \mathrm{P}<0.05$ \\
\hline
\end{tabular}




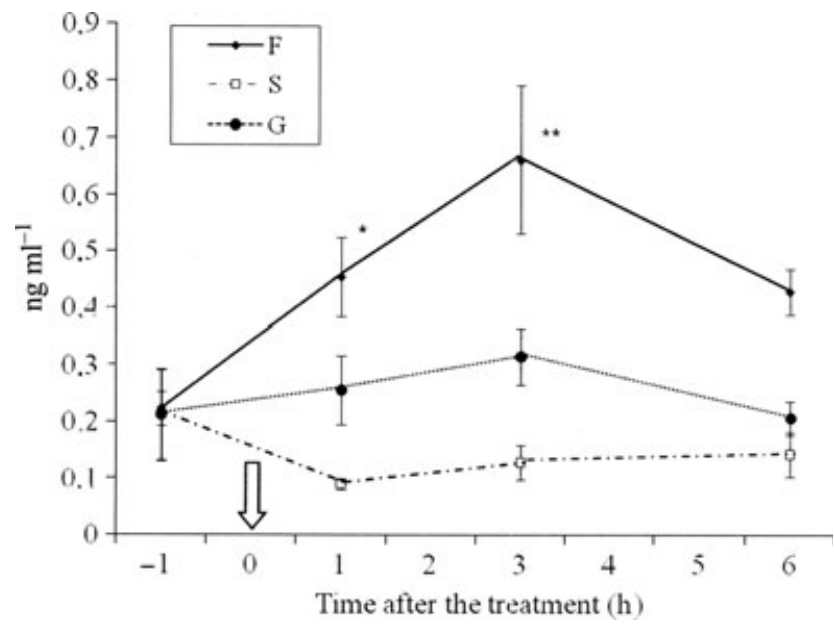

Fig. 1. Serum profiles of free (F) 17,20 $\beta$,21-trihydroxy-4-pregnen-3one $(20 \beta \mathrm{S})$ and its conjugated forms (S- sulphate; $\mathrm{G}-$ glucuronide) in stellate sturgeon males after exposure to female coelomic fluid adding $2 \mathrm{~min}$ interval for $0.5 \mathrm{~h}$ to tank water. Data present mean and standard error of the mean (SE). The serum unknown samples have been analyzed in duplicates; number of examined fish was $7(\mathrm{n}=7)$. Differences are significant in comparison to the initial levels: $* \mathrm{P}<0.05 ; * * \mathrm{P}<0.01$. Arrow indicates the time of the treatment

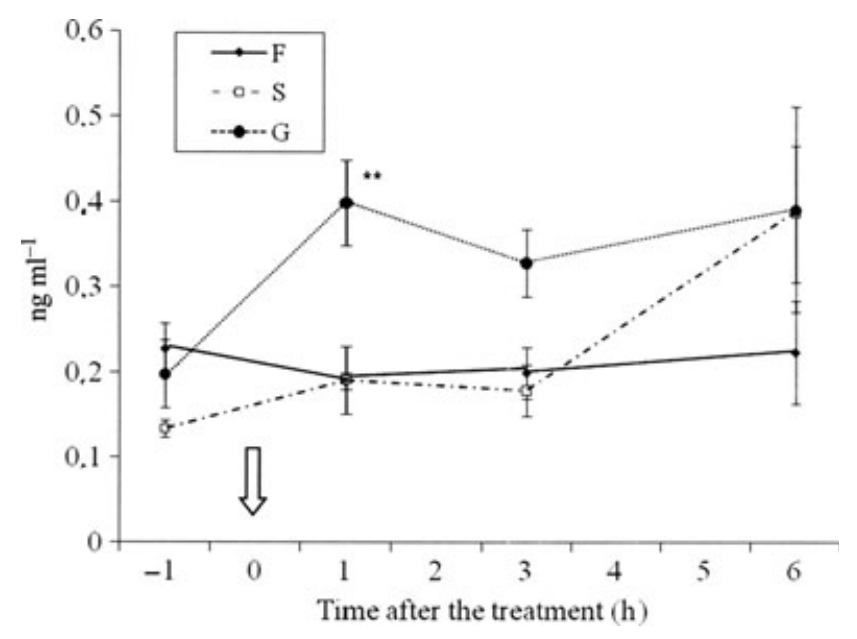

Fig. 2. Serum profiles of free (F) 17,20 $\beta$-dihydroxy-4-pregnen-3-one (DHP) and its conjugated forms (S- sulphate; G - glucuronide) in stellate sturgeon males after exposure to female coelomic fluid adding 2 min interval for $0.5 \mathrm{~h}$ to tank water. Data present mean and standard error of the mean (SE). The serum unknown samples have been analyzed in duplicates; number of examined fish was $7(n=7)$. Differences are significant in comparison with the initial levels: $* * \mathrm{P}<0.01$. Arrow indicates the time of the treatment

than in the blood serum; conversely, $\mathrm{P}_{4}$ levels were high in $\mathrm{CF}$ than in the blood (Barannikova et al., 2002). In our experiment, $\mathrm{P}_{4}$ levels as well as sulphated and glucuronidated $\mathrm{T}$ levels are similar in serum and $\mathrm{CF}$. We observed no significant differences between free and conjugated sex steroids levels in $\mathrm{CF}$ but there were positive correlations between free T, DHP, $\mathrm{S}$ levels and conjugated forms of these steroids in $\mathrm{CF}$. The observations suggest that the certain levels of sex steroids in $\mathrm{CF}$ may be required to maintain ovulated eggs in a viable state. Similar levels of free and conjugated gonadal steroids we observed early in CF in stellate sturgeon females. According to the previous observations, the serum levels of free $\mathrm{T}$ and its sulphate peaked $10-13 \mathrm{~h}$ after LH-RH-A treatment and decreased during ovulation, and so did free serum DHP levels; free $20 \beta \mathrm{S}$ and $\mathrm{S}$ serum levels significantly elevated $7-10 \mathrm{~h}$ after

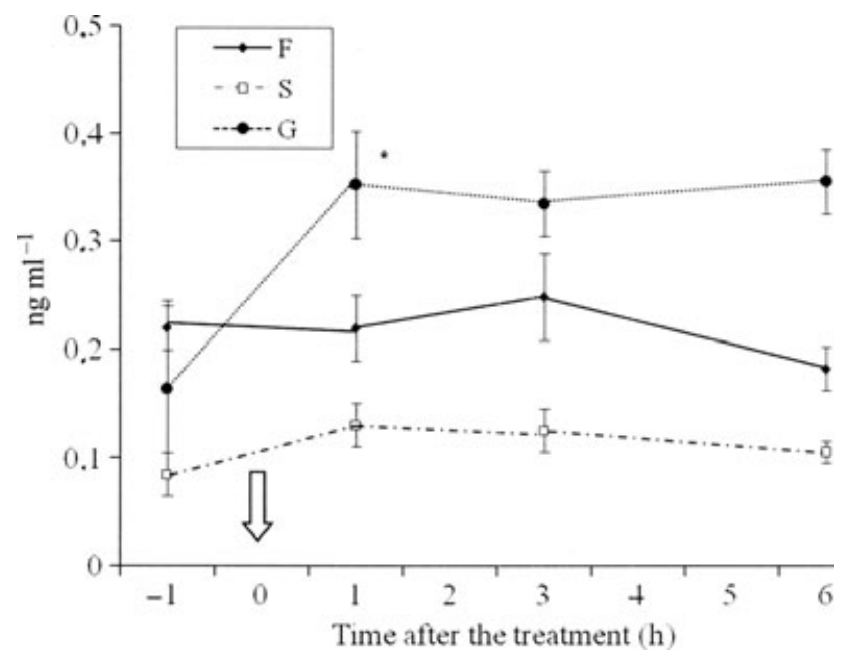

Fig. 3. Serum profiles of free (F) 11-desoxycortisol (S) and its conjugated forms (S- sulphate; $\mathrm{G}$ - glucuronide) in stellate sturgeon males after exposure to female coelomic fluid adding 2 min interval for $0.5 \mathrm{~h}$ to tank water. Data present mean and standard error of the mean (SE). The serum unknown samples have been analyzed in duplicates; number of examined fish was $7(\mathrm{n}=7)$. Differences are significant in comparison with the initial levels: $* \mathrm{P}<0.05$. Arrow indicates the time of the treatment

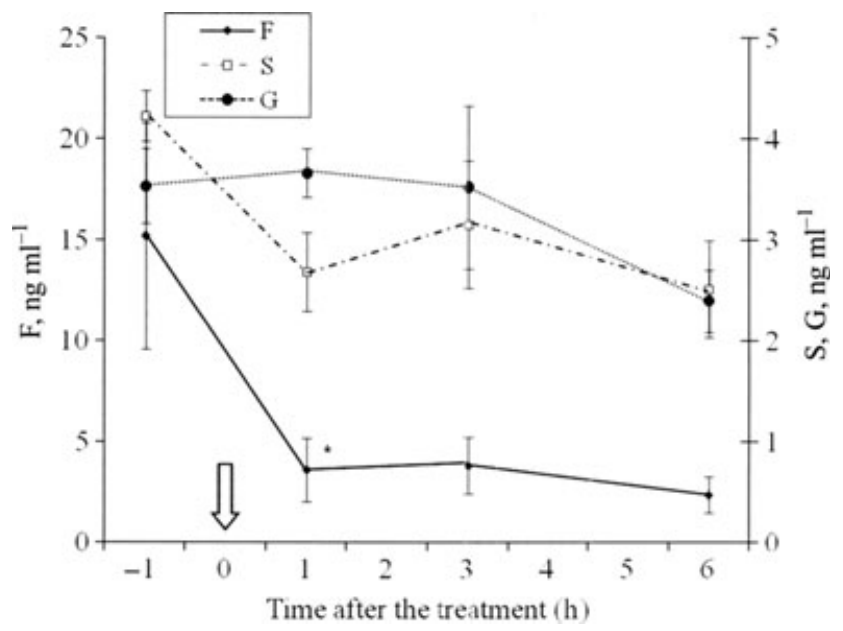

Fig. 4. Serum profiles of free (F) 11-ketotestosterone (11KT) and its conjugated forms (S- sulphate; $\mathrm{G}$ - glucuronide) in stellate sturgeon males after exposure to female coelomic fluid adding 2 min interval for $0.5 \mathrm{~h}$ to tank water. Data present mean and standard error of the mean (SE). The serum unknown samples have been analyzed in duplicates; number of examined fish was $7(n=7)$. Differences are significant in comparison with the initial levels: ${ }^{*} \mathrm{P}<0.05$. Arrow indicates the time of the treatment

the treatment, as well as their sulphates (Bayunova et al., 2008a). Taken together the data suggest that these forms of sex steroids could be part of a chemical communication system related to reproductive behaviour in sturgeons. In the European eel (Anguilla anguilla), sexually maturing breeders were able to stimulate spermatogenesis of immature males; release into water of free and conjugated forms of sex steroids by spermiating males and pre-ovulatory and ovulating females have induced high electro-olfactograms in neighbouring immature males (Huertas et al., 2006).

The observations by Kasumyan (1993) on the male swimming activity in the Russian sturgeon (Acipenser gueldenstaedtii) as a behavioural reaction to the female releaser post-ovulatory pheromone of $\mathrm{CF}$ have been visually supported by our 


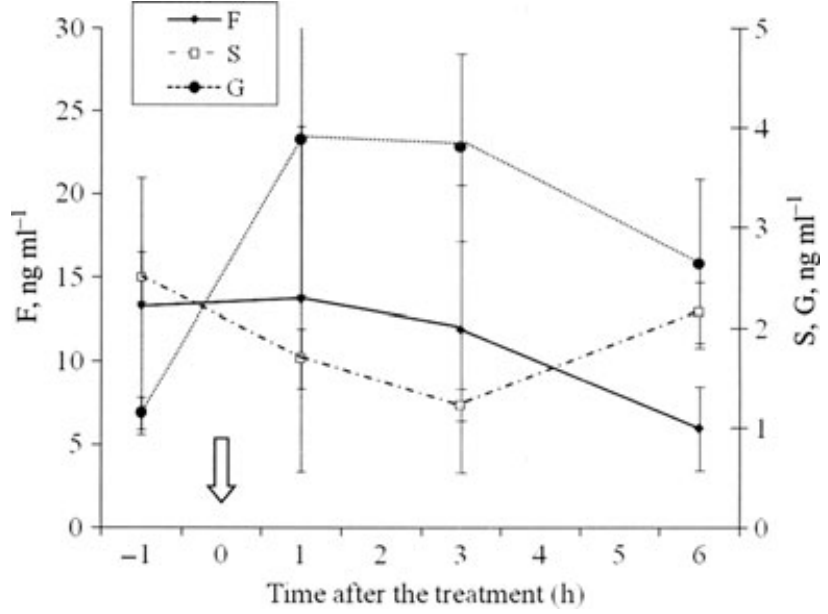

Fig. 5. Serum profiles of free $(F)$ testosterone $(T)$ and its conjugated forms ( $\mathrm{S}$ - sulphate; $\mathrm{G}$ - glucuronide) in stellate sturgeon males after exposure to female coelomic fluid adding $2 \mathrm{~min}$ interval for $0.5 \mathrm{~h}$ to tank water. Data present mean and standard error of the mean (SE). The serum unknown samples have been analyzed in duplicates; number of examined fish was $7(n=7)$. Arrow indicates the time of the treatment

experiment of the same kind. In the American eel (Anguilla rostrata), odours released by sexually mature females have been suggested to serve as short-range attractants that affect the spawning behaviour of males (Briand et al., 2002). In the Eurasian ruffe (Gymnocephalus cernuus), ovulatory female undergoing oocyte maturation release a cue that strongly stimulates locomotor and sexual activity of male conspecifics and pheromone production was associated with elevated plasma levels of $20 \beta \mathrm{S}$ in maturing females (Sorensen et al., 2004).

Our data have demonstrated the change of free and conjugated sex steroid levels as a response of males to the female CF treatment. Free $20 \beta \mathrm{S}$ levels are significantly increased after the treatment and decreased at the end of the experiment; glucuronidated DHP and S levels are elevated after the treatment; free $11 \mathrm{KT}$ and $\mathrm{T}$ levels are decreased after the treatment. The research has already shown that fish excrete steroid metabolites (including pheromones) into water via urine, gills and bile (see review by Scott and Ellis, 2007); and it is recognized that $\mathrm{CF}$ is also the source of post-ovulatory pheromones in fish (Stacey and Goetz, 1982; Kasumyan, 1993). Greenwood et al. (2001) have observed a strong correlation between the amounts of steroids (free, sulphated and glucuronidated DHP) in blood and water after hormonal stimulation of FM in common dentex (Dentex dentex). Pavlidis et al. (2004) observed that the water concentrations of some free and conjugated steroids were related to the number of males and females (sex ratio) in the tank for common dentex. Free and glucuronidated DHP concentrations were elevated in plasma and released into water by female and male tench (Tinca tinca) after hormonal stimulation of FM and the steroids were detected by the male olfactory epithelium (Pinillos et al., 2002). According to our previous experiment, free and conjugated sex steroid levels (especially free $20 \beta \mathrm{S}$ and conjugated DHP) were elevated in blood serum and urine at spermiation being induced by $\mathrm{LH}-$ RH-A in stellate sturgeon males (Bayunova et al., 2008b). Summing up, the steroids may play pheromonal role related to the reproduction in fish, including sturgeon.

In conclusion, the rise of free and conjugated sex steroid levels in stellate sturgeon male blood serum and the elevation of their speed activity after $\mathrm{CF}$ treatment suggest that the components of $\mathrm{CF}$ including free and conjugated forms of sex steroids can play significant role in sturgeon pheromonal communication. Therefore, the further studies are of great importance to identify the chemical nature of potential pheromones in sturgeons.

\section{Acknowledgements}

The authors cordially thank E. Couto for $20 \beta$ S and DHP measurement by RIA and Dr. D. Kime for their gift of antiserum against $11 \mathrm{KT}$ for ELISA. This study was supported by a Collaborative Linkage Grant Ref. №: LST.CLG.979493 of the NATO Science Programme, Cooperative Science and Technology Sub-Programme.

\section{References}

Barannikova, I. A.; Dyubin, V. P.; Bayunova, L. V.; Semenkova T. B., 2002: Steroids in the control of reproductive function of fish. Neurosci. Behav. Physiol. 32, 141-148.

Bayunova, L. V.; Barannikova, I. A.; Dyubin, V. P.; Gruslova, A. B.; Semenkova, T. B.; Trenkler, I. V., 2003: Sex steroids concentration in sturgeon (Acipenser gueldenstaedtii Brandt) serum and coelomic fluid at final maturation. J. Fish Physiol. Biochem. 28, 325-326.

Bayunova, L.; Semenkova, T.; Canario, A.; Couto, E.; Gerasimov, A.; Barannikova, I., 2008a: Levels of free and conjugated androgens and progestins in coelomic fluid and serum of stellate sturgeon (Acipenser stellatus Pallas) females. Cybium 32(Suppl. 2), 275-276.

Bayunova, L.; Canario, A.; Semenkova, T.; Couto, E.; Gerasimov, A. Barannikova, I., 2008b: Free androgens, progestins and their conjugated forms in serum and urine of stellate sturgeon (Acipenser stellatus Pallas) males. Cybium 32(Suppl. 2), 273-274.

Briand, C.; Fatin, D.; Leagult, A., 2002: Role of eel odour on the efficiency of an eel, Anguilla anguilla, ladder and trap. Environ. Biol. Fish 65, 473-477.

Burnard, D.; Gozlan, R. E.; Griffiths, S. W., 2008: The role of pheromones in freshwater fishes. J. Fish Biol. 73, 1-16.

Canario, A. V. M.; Scott, A. P., 1989: Synthesis of 20 $\alpha$-hydroxylated steroids by ovaries of the dab (Limanda limanda). Gen. Comp. Endocrinol. 76, 147-158.

Ginsburg, A. S.; Dettlaff, T. A., 1969: Development of sturgeons. Nauka, Moscow. USSR. 134 pp. (in Russian).

Greenwood, L. N.; Scott, A. P.; Vermeirssen, E. L. M.; Mylonas, C. C.; Pavlidis, M., 2001: Plasma steroids in mature common dentex (Dentex dentex) stimulated with a gonadotropin-releasing hormone agonist. Gen. Comp. Endocrinol. 123, 1-12.

Huertas, M.; Scott, A. P.; Hubbard, P. C.; Canário, A. V.; Cerdà, J., 2006: Sexually mature European eels (Anguilla anguilla L.) stimulate gonadal development of neighbouring males: possible involvement of chemical communication. Gen. Comp. Endocrinol. 147, 304-313.

Kasumyan, A. O., 1993: Behavioral reaction of male sturgeons to the releaser postovulatory sex pheromone of females. Dokl. Biol. Sci. 333, 402-404. (in Russian).

Kime, D. E., 1993: "Classical" and "non-classical" reproductive steroids in fish. Rev. Fish Biol. Fisheries 3, 160-180.

Kobayashi, M.; Sorensen, P. W.; Stacey, N. E., 2002: Hormonal and pheromonal control of spawning behavior of the goldfish. Fish Physiol. Biochem. 26, 71-84.

Lahnsteiner, F., 2002: The influence of ovarian fluid on the gamete physiology in the Salmonidae. Fish Physiol. Biochem. 27, 49-59.

Lahnsteiner, F.; Weismann, T., 1999: Changes in eggs of brown trout, rainbow trout, and grayling during short term storage. N. Am. J. Aquac. 61, 213-219.

Pavlidis, M.; Greenwood, L.; Scott, A. P., 2004: The role of sex ratio on spawning performance and on the free and conjugated sex steroids released into the water by common dentex (Dentex dentex) broodstock. Gen. Comp. Endocrinol. 138, 255-262.

Pinillos, M. L.; Guijarro, A. I.; Delgado, M. J.; Hubbard, P. C.; Canario, A. V. M.; Scott, A. P., 2002: Production, release and olfactory detection of sex steroids by the tench (Tinca tinca L.). Fish Physiol. Biochem. 26, 197-210. 
Scott, A. P.; Canario, A. V. M., 1992: 17 $\alpha$, 20 $\beta$-dihydroxy-4-pregnen3-one 20-sulphate; a major new metabolite of the teleost oocyte maturation-inducing steroid. Gen. Comp. Endocrinol. 85, 91-100.

Scott, A. P.; Ellis, T., 2007: Measurement of fish steroids in water - a review. Gen. Comp. Endocrinol. 153, 392-400.

Scott, A. P.; Vermeirssen, E. L. M., 1994: Production of conjugated steroids by teleost gonads and their role as pheromones. In: Perspectives in comparative endocrinology. K. G. Davey, R. E. Peter and S. S. Tobe (Eds), National Research Council of Canada, Ottawa, pp. 645-654.

Semenkova, T. B.; Barannikova, I. A.; Kime, D. E.; McAllister, B. G.; Bayunova, L. V.; Dyubin, V. P.; Kolmakov, N. N., 2002: Sex steroid profiles in female and male Stellate sturgeon during final maturation induced by hormonal treatment. J. Appl. Ichthyol. 18, 375-381.

Sorensen, P. W.; Stacey, N. E., 2004: Brief review of fish pheromones and discussion of their possible uses in the control of nonindigenous teleost fishes. N. Z. J. Mar. Freshw. Res. 38, 399-417.
Sorensen, P. W.; Murphy, C. A.; Loomis, K.; Maniak, P.; Thomas, P., 2004: Evidence that 4-pregnen-17,20b,21-triol-3-one functions as a maturation inducing hormone and pheromone precursor in the percid fish, Gymnocephalus cernuus. Gen. Comp. Endocrinol. 139, $1-11$.

Stacey, N. E.; Goetz, F. W., 1982: Role of prostaglandins in fish reproduction. Can. J. Fish. Aquat. Sci. 39, 92-98.

Stacey, N. E.; Sorensen, P. W., 2002: Fish hormonal pheromones. In: Hormones, brain, and behavior. D. W. Pfaff, D. Arnold, A. Etgen, S. Fahrbach and R. Rubin (Eds), Academic Press, San Diego. Vol. 2, pp. 375-435.

Author's address: Liubov Bayunova, Central Laboratory of Fish Reproduction, 24, prof. Popova str., St Petersburg, 197022, Russia.

E-mail: bayunoval@mail.ru 